\title{
Razones y estrategias para la conservación de los recursos genéticos animales.
}

\author{
Revisión
}

José C. Segura-Correa, Rubén C. Montes-Pérez.

Facultad de Medicina Veterinaria y Zootecnia, Universidad Autónoma de Yucatán. Mérida, Yucatán, México.

\section{RESUMEN.}

Se realizó una revisión de literatura sobre la importancia de los recursos genéticos animales y las estrategias para su conservación. Se reconoce la pérdida de material biológico y una reducción en la variabilidad genética. Las estrategias para la conservación de los recursos deben consistir en la realización de encuestas, la determinación de las poblaciones animales, la caracterización fenotípica y genotípica de ellos y el manejo de la variación genética. La conservación de los recursos puede ser in situ o ex situ. Con respecto a la segunda forma se revisan los aspectos de la criopreservación del material genético la cual tiene amplias perspectivas. (Rev Biomed 2001; 12:196-206)

Palabras clave: Biodiversidad, recursos, genéticos.

SUMMARY.

Reasons and strategies for the conservation of animal genetic resources.

A literature review was carried out on the importance of the animal genetic resources and the strategies for its conservation. The loss of biological material is acknowledged as well as a reduction in genetic variability. The strategies for the conservation of the genetic resources should include the application of survey, the determination of the animal populations, its phenotypic and genotipic characterization and management of the genetic variability. Conservation of the resources could be by in situ or ex situ means. Cryopreservation is reviewed because of its wide perspectives. (Rev Biomed 2001; 12:196-206)

Key words: Genetic variability, genetics resources.

\section{INTRODUCCIÓN.}

Por diversidad biológica o biodiversidad, se entiende la variedad total de estirpes genéticas,

Solicitud de sobretiros: Dr. José C. Segura-Correa, Facultad de Medicina Veterinaria y Zootecnia, Universidad Autónoma de Yucatán. Apdo. 4-116. C.P.97100. Mérida, Yucatán. E-mail: scorrea@tunku.uady.mx 


\section{JC Segura-Correa, RC Montes-Pérez.}

especies y ecosistemas (1).

Al nivel de comunidades biológicas la biodiversidad ha sido determinada con base en los componentes que la pueden definir en un tiempo y lugar determinados, algunos de éstos son la riqueza, abundancia relativa y dominancia de especies. Se han propuesto diferentes índices para estimarla como el de Simpson o el de Shannon-Wiener, cada uno de éstos estima la biodiversidad de acuerdo al componente que se pretende resaltar y el objetivo para la estimación de ésta (2). Así por ejemplo, la estimación de la biodiversidad a partir de la diversidad específica proporciona valores que fluctúan entre 10 y 100 millones de especies distintas en el planeta (3).

La diversidad biológica cambia continuamente determinada por las fuerzas evolutivas, en especial la selección natural y mutaciones genéticas, que dan lugar a nuevas especies; y a su vez, las nuevas condiciones ecológicas ocasionan la desaparición de otras especies. Según fundamentos de la Unión Internacional para Conservación de la Naturaleza (UICN), el Programa de las Naciones Unidas para el Medio Ambiente (PNUMA) y el Fondo Mundial para la Vida Silvestre (WWF) la diversidad biológica debe conservarse como una cuestión de principio, pues todas las especies merecen respeto, independientemente de si son o no de utilidad para la humanidad (4). Desde el punto de vista económico, la biodiversidad tiene valor: el de uso y opción. El primero se refiere a los beneficios en productos o servicios que se obtienen de vegetales, animales, hongos y microorganismos para el bienestar de la humanidad, el segundo se dirige al beneficio potencial que tendrían poblaciones que actualmente no tienen demanda económica, como es el caso de vegetales considerados como malezas los cuales tienen una función importante en la estabilidad de agrosistemas (5).

Las poblaciones que tienen rasgos genéticos particulares y únicos se denominan recursos genéticos. Con base en el valor de uso que tienen los recursos genéticos, las poblaciones de animales domésticos y de especies silvestres relacionadas constituyen los recursos genéticos animales $(6,7)$.

Latinoamérica posee una amplia diversidad de recursos genéticos animales, los cuales son utilizados en diferentes sistemas y bajo variadas condiciones ecológicas y sociales. Algunos de estos recursos poseen características que son únicas a ambientes específicos y que están sufriendo una dilución genética o extinción. Estos recursos a través de la selección natural y selección realizada por el hombre han desarrollado características que los hacen bien adaptados a las condiciones ambientales bajo las cuales los animales tienen que vivir y producir. Este valioso material genético necesita ser mantenido y mejorado como la base para políticas y programas nacionales de mejoramiento $(7,8)$.

Los problemas a que se enfrentan los recursos genéticos animales en el mundo son según expertos de la FAO (5): 1) la disminución de la variabilidad genética dentro de razas; esto es básicamente un problema de las razas o líneas altamente productivas mantenidas en zonas templadas y empleadas en sistemas intensivos de producción; 2) la rápida desaparición de razas locales y líneas de animales domésticos a través de la introducción de razas exóticas y 3) los climas cálidos y húmedos y otros ambientes hostiles comunes a los países en desarrollo. En reconocimiento a ello, varios esfuerzos se están haciendo para desarrollar programas y proyectos sobre el manejo y conservación de los recursos genéticos animales. Tales esfuerzos incluyen las diversas reuniones celebradas en el ámbito nacional, regional e internacional. Por ejemplo, en 1978, la FAO realizó la primera reunión de expertos sobre la conservación del ganado criollo en Bogotá, Colombia; en 1988 celebró en Roma, Italia, otra reunión sobre los recursos genéticos animales, siendo en esta ocasión una preocupación el desarrollar programas de manejo y conservación de acuerdo con los sistemas de producción sostenibles; en 1992 Realiza una reunión sobre la conservación de los recursos genéticos animales, en la que se recomiendan programas de acción

\section{Revista Biomédica}


Recursos genéticos animales.

sobre conservación, preservación (in situ y ex situ), monitoreo, criterios y razones de conservación, biotecnología, banco de datos y genes (9). En ese mismo año se realiza en Costa Rica, una reunión sobre "Programas de Conservación y Manejo de los Recursos Genéticos Animales de Latinoamérica y el Caribe" (10), en la cual 15 países presentaron los programas, que sobre el manejo de los recursos genéticos animales realiza o planea realizar cada uno. Se encontró que los programas variaban en nivel y magnitud, desde los países que tienen programas estructurados hasta los que no tenían programas de manejo y conservación de los recursos genéticos animales. También quedo claro que existen diferencias entre países en las especies que consideran merecen atención nacional e internacional. Esto fue especialmente cierto con respecto a los pequeños rumiantes, camélidos, cuyes y aves domésticas (10).

Recientemente, Alonso y Ulloa (11) propusieron el Proyecto Nacional de Investigación en Genomas de Animales Domésticos, que por su contenido es análogo al Programa Nacional de Germoplasma Animal establecido en Estados Unidos de Norteamérica. Ambos programas tienen por objetivo identificar, estudiar, conservar y utilizar adecuadamente los recursos genéticos animales, para disponer de genes y complejos genéticos que sustentan las fuentes alimenticias y el desarrollo industrial en este continente.

\section{RAZONES PARA LA CONSERVACIÓN DE LOS RECURSOS GENÉTICOS ANIMALES}

El ganado criollo (Bos taurus) traído por los conquistadores a México ha sido reemplazado por razas de ganado Bos índicus el cual ahora sufre el desplazamiento de razas Europeas mejoradas o por las cruzas entre éstas. Similar situación se presenta en otras especies como las aves en donde las gallinas criollas han sido reemplazadas por líneas de gallinas mejoradas para la producción comercial de alimentos para la población humana $(12,13)$.

El desplazamiento de las razas nativas y criollas se atribuye en parte, a la elevada tasa de crecimiento poblacional y su desplazamiento hacia las ciudades. Por lo que para satisfacer la demanda de alimentos para esa población hubo la necesidad de aumentar la productividad de algunas especies de animales a través de la intensificación de los sistemas de producción. Sin embargo, la característica de los sistemas comerciales es la homogeneidad de las razas y líneas utilizadas a expensas de la diversidad. Cuando se seleccionan individuos buscando determinados rasgos que respondan a las necesidades de una producción especializada - por ejemplo, eligiendo a los animales más productores de huevos, leche o carnese descartan otras características, como la adaptabilidad al clima, la resistencia a ciertas enfermedades o la capacidad para vivir con los recursos locales (14).

Existen además otras razones para preservar los recursos genéticos. Comte (15) menciona que "la diversidad genética entre los animales merece ser preservada para las generaciones futuras del mismo modo que el arte y la arquitectura". Por otro lado, la diversidad de la naturaleza constituye la fuente de la riqueza biológica y es la base de nuestros alimentos, de muchas materias primas y de los materiales genéticos para la agricultura, la medicina y la industria.

En México, aún existen razas de animales criollos no claramente definidas, debido a que se tienen poblaciones de animales geográficamente separadas, con una multitud de tipos locales, los cuales están siendo usados. Estos animales presumiblemente están bien adaptados a las condiciones climáticas y de manejo de la región; sin embargo, aún cuando esos animales están siendo utilizados su comportamiento y adaptación se desconocen y se encuentran bajo la amenaza de una dilución genética o reemplazo por animales mejorados. La alta producción de las líneas y/o razas mejoradas de los países desarrollados en comparación con las razas nativas de los países en desarrollo, ha conducido a la expectativa irreal de un rápido mejoramiento de la productividad a través de la importación. Sea la importación y 


\section{JC Segura-Correa, RC Montes-Pérez.}

cruzamiento con razas criollas planeada o no, el resultado podría ser la pérdida de material genético criollo antes que su potencial real sea conocido. Los esfuerzos por evaluar las razas criollas deberían tener prioridad y para ello la conservación de éstas es necesaria. Sin embargo, el objetivo primordial no deberá ser la preservación como tal de animales en extinción, sino su evaluación y utilización. La elección de las razas que deben ser conservadas debe basarse en características de adaptación tales como la rusticidad y habilidad combinatoria al cruzarse con otras razas. Esto implica entonces el desarrollo de programas de mejoramiento genético para incrementar la productividad y eficiencia bajo las condiciones de manejo existentes en las regiones donde se producen. En los países en desarrollo donde hay incertidumbre acerca de las condiciones futuras de producción y de mercado y, además existe en estos mismos sistemas de producción ambientes desfavorables, la conservación de la diversidad genética y el mejoramiento de los recursos genéticos animales locales tienen una gran importancia, porque representan recursos alternativos para mantener la producción animal bajo cualquier cambio drástico de tipo ambiental o económico, luego entonces tiene más sentido la introducción de nueva tecnología en los países tropicales, para conservar y mejorar sus recursos que la introducción de razas no adaptadas provenientes de zonas templadas (16).

\section{ESTRATEGIAS PARA LA CONSERVACIÓN DE LOS RECURSOS GENÉTICOS ANIMALES.}

Las principales actividades a realizar para la conservación y manejo de los recursos genéticos animales de acuerdo con Steane (17), se discuten a continuación:

\section{1.- Encuesta y determinación de la población de animales domésticos.}

Los conocimientos que se disponen sobre el estado y distribución de muchas especies de animales aún son limitados, sobre todo en los países de Latinoamérica. La estimación precisa de la identidad y abundancia de razas, líneas y población de animales de actual o potencial importancia agrícola es el primer paso hacia la implementación de un programa de conservación. Mientras esta carencia persista las medidas de conservación distaran de ser eficientes. Por tanto, se requiere un extensivo programa nacional o regional, para evaluar el germoplasma que necesita conservarse por razones biológicas, económicas, ecológicas o sociales. El reporte de la FAO describe las estrategias de manejo para poblaciones que requieren preservarse de acuerdo con el número de hembras reproductoras. La federación Europea de Zootecnia estableció que la calificación "en peligro" se otorgue cuando la cifra fuera inferior a 1000 vacas, 500 ovejas o cabras y 200 cerdas. Sin embargo, debido al aislamiento genético, a las condiciones climáticas y a los grandes riesgos sanitarios, el tamaño de las poblaciones deben duplicarse o triplicarse en los países en desarrollo (15).

La decisión respecto a que si una especie debe ser conservada deberá hacerse después de una encuesta satisfactoria y caracterización completa de la especie.

\section{2.- Caracterización fenotípica y genotípica de los recursos genéticos animales.}

La población de muchas especies de animales nativos o criollos de Latinoamérica y el Caribe ha sido reducida en número debido a: 1) la introducción de animales exóticos; 2) destrucción del habitat ecológico de los animales criollos; 3) sobreexplotación; 4) pérdida de interés económico o 5) enfermedades. Un problema de especial interés es que muy pocas razas y líneas de animales en los países en desarrollo han sido caracterizadas adecuadamente por sus rasgos productivos y aptitud. La introducción de razas "mejoradas" a los países en desarrollo es generalmente a expensas de las razas criollas o nativas adaptadas a las condiciones locales a través de la selección natural.

\section{Revista Biomédica}


Recursos genéticos animales.

A menudo, los efectos del vigor híbrido del cruzamiento enmascaran la pérdida de adaptación genética (18). La caracterización fenotípica o genotípica permitirá la comparación con otras poblaciones.

Con nuevas técnicas para la caracterización del genoma a nivel molecular como el DNA polimórfico amplificado aleatoriamente (RAPD por sus siglas en inglés), el polimorfismo de la longitud de los fragmentos de restricción (RFLP también por sus siglas en inglés) y los Tandem repetidos de número variable (VNTR), han permitido el establecimiento de bancos de información de cadenas nucleotídicas que facilitan la identificación y utilización de marcadores genéticos que son usados para el diagnóstico de enfermedades en humanos (19), o para efectuar el mapeo genético de bovinos y cerdos (20-22).

Steane (17) proporciona un formato que incluye información para: datos de comportamiento, descriptores cualitativos, origen y desarrollo de la raza, peculiaridades genéticas, parámetros genéticos y comparación de razas. En adición a los rasgos del animal, es necesario describir suficientemente el ambiente. El conocimiento del ambiente en el cual ocurre la caracterización puede ser usado para predecir el comportamiento de la población en otros ambientes.

En México, la investigación sobre el manejo de los recursos genéticos animales es precaria, como lo indica la escasez de publicaciones sobre este tópico en las principales revistas científicas del país. Los escasos trabajos se han enfocado al estudio de los sistemas de producción y son de tipo descriptivo, realizados a través de encuestas estáticas en las que se caracteriza a la ganadería de traspatio (23-25). Otros por ejemplo, fueron destinados a la caracterización genética de ganado bovino criollo y cruzas por medio del polimorfismo genético de proteínas sanguíneas $(26,27)$.

La Universidad Autónoma de Yucatán es una de las pocas instituciones que a la fecha tiene un proyecto de caracterización y comportamiento productivo de animales criollos, en especial las gallinas criollas, con un tamaño efectivo de población mayor de 50, recomendado por la FAO para establecer un núcleo reproductor (13).

\section{3.- Implementación de biotecnologías para la conservación de la variación genética.}

El material genético puede ser preservado según Lake (16) de tres maneras:

i) Conservando y reproduciendo una población in situ.

ii) Conservación ex situ (Congelando gametos y embriones), $y$

iii) Almacenamiento y transferencia de núcleos y DNA en un banco de genes.

\section{i- Conservación y reproducción de una población in situ.}

La conservación in situ permite a la población animal y al ambiente evolucionar juntos e implica la conservación de los animales en el ambiente bajo el cual se han desarrollado o en el agrosistema donde están produciendo. En un enfoque más amplio, la conservación in situ también incluye el manejo del ecosistema para la producción sustentable de alimento (7).

El principal problema técnico de la conservación para los diseños in situ es el muestreo de los animales. Se sugiere que, para mantener una mayor variabilidad genética, el número de machos a usar debe ser mayor que el número requerido en los esquemas de reproducción comercial. Si la retrocruza es posible, machos de la raza a conservar deben ser apareados con hembras de otra raza hasta absorberlas por cuatro o más generaciones y entonces las crías podrían ser consideradas como una población de animales conservados.

En rumiantes y otras especies el cruzamiento con los mejores animales utilizando un sistema reproductivo de núcleos abiertos podría facilitar el programa de manejo genético y mejoramiento de la raza, línea o población. El sistema reproductivo de núcleos abiertos ha sido recomendado por Steane (17) combinado con la técnica de Ovulación Múltiple y Transferencia de

Vol. 12/No. 3/Julio-Septiembre, 2001 


\section{JC Segura-Correa, RC Montes-Pérez.}

Embriones (OMTE). OMTE permite potencialmente un progreso mayor en los países en desarrollo que los métodos tradicionales de selección animal (10). En la práctica, se establece un núcleo genéticamente superior de un rebaño o un hato investigando la población básica de hembras sobresalientes. A estas hembras "elite" se les aplica OMTE para obtener embriones que serán transplantados a vacas receptoras de la población base. Las crías resultantes son evaluadas genéticamente y de ellas se seleccionan los mejores machos como reproductores, que son usados para mejorar la población base, mediante servicio natural así como por inseminación artificial (15).

Una segunda razón para utilizar poblaciones de hembras cruzadas es que la población nativa puede ser seguida por su linaje mitocondrial. El DNA mitocondrial es considerado una fuente adicional de variación genética entre líneas dentro de una raza o población y puede permitir la cuantificación de fuentes importantes de variación genética extranuclear. El DNA mitocondrial es importante también para estimar la distancia genética entre poblaciones.

Para conservar a una especie de interés es indispensable contar con una población relativamente grande de animales para reducir los problemas de consanguinidad normalmente asociados a poblaciones pequeñas. Ejemplos de los efectos de los aumentos en la consanguinidad sobre algunos rasgos de interés económico en los animales domésticos se presentan en el Cuadro 1. Los efectos de consanguinidad son usualmente más detrimentales para rasgos de sobrevivencia y reproducción que para rasgos de crecimiento o calidad del producto. La mejor opción para reducir el efecto de la consanguinidad parece ser el esquema de mínima consanguinidad en el cual cada macho y cada hembra contribuyen con una cría a la siguiente generación y evitando el apareamiento entre parientes (28). Sin embargo, factores técnicos y económicos generalmente limitan el número total de individuos a muestrear y/o el número de gametos o embriones a preservar por individuo. Smith (29) identificó tres principios que deben aplicarse cuando esas limitantes están presentes:

a) Muestrear más lotes o hatos eligiendo pocos individuos de cada lote, en vez de seleccionar muchos individuos de pocos lotes o hatos.

b) Conservar lotes que son genética y fenotípicamente diferentes en vez de aquellos que son similares.

c) Conservar lotes como líneas puras en vez de grupos genéticos para mantener diversas combinaciones de rasgos influenciados genéticamente y para proveer futura flexibilidad en recombinación de los lotes conservados.

\section{ii.- Conservación ex situ de los recursos genéticos animales.}

Ex situ es el mantenimiento de una población fuera de su ambiente normal y la criopreservación de gametos y/o embriones.

\section{ii.1) Criopreservación de espermatozoides.}

El descubrimiento del glicerol como agente crioprotector de las células condujo al primer Cuadro 1

Ejemplos de depresión endogámica en los animales domésticos.

\begin{tabular}{|c|c|c|}
\hline \multirow[t]{2}{*}{ Carácter } & \multicolumn{2}{|c|}{$\begin{array}{l}\text { Depresión endogámica por } 10 \% \text { de } \\
\text { incremento en la consanguinidad. }\end{array}$} \\
\hline & Unidades & $\%$ \\
\hline \multicolumn{3}{|l|}{ Bovinos: } \\
\hline Producción de leche & $-13.5 \mathrm{~kg}$ & -3.2 \\
\hline \multicolumn{3}{|l|}{ Porcinos: } \\
\hline Tamaño de camada & -0.38 crías & -4.6 \\
\hline Peso a los 154 días & $-1.44 \mathrm{~kg}$ & -2.7 \\
\hline \multicolumn{3}{|l|}{ Ovinos: } \\
\hline Peso del vellón & $-0.25 \mathrm{~kg}$ & -5.5 \\
\hline Peso al año de edad & $-1.15 \mathrm{~kg}$ & -3.7 \\
\hline \multicolumn{3}{|l|}{ Aves: } \\
\hline Producción de huevo & -9.3 huevos & -6.2 \\
\hline Incubabilidad & $-4.4 \%$ & -6.4 \\
\hline Peso corporal & $-15.7 \mathrm{~g}$ & -0.8 \\
\hline
\end{tabular}

De acuerdo a Falconer (43)

\section{Revista Biomédica}


método de congelamiento de espermatozoides con viabilidad aceptable para ser usados en la inseminación artificial (IA). En los bovinos, el congelamiento de semen en nitrógeno líquido para posteriormente usarse por IA, es una técnica muy utilizada en los países desarrollados y también en los países en desarrollo, pero con menor frecuencia (30).

El congelamiento del semen permitiría la conservación del material genético contenido en los espermatozoides por lo tanto, es de gran valor para conservar la diversidad genética. Al igual que en la transferencia de embriones, el riesgo y costo del transporte de semen es menor que el transporte del animal para servicio natural. Así mismo, el uso de semen congelado puede eliminar las cuarentenas y disminuir los riesgos de la transmisión de enfermedades (30).

\section{ii.2) Criopreservación de embriones y óvulos.}

En los últimos años las técnicas sobre la colección, almacenamiento y transferencia de embriones de bovinos han sido simplificadas considerablemente con el desarrollo de técnicas no quirúrgicas y métodos para conservar embriones. La transferencia de embriones se ve limitada, hasta ahora, por las diferencias en la reacción de animales donadores a la superovulación y a los costos de la técnica (30). Sin embargo, en algunos países el congelamiento de embriones de ganado bovino se aplica comercialmente (31). Cabe mencionar que la criopreservación ha sido utilizada como un método de almacenamiento de material genético en algunos animales domésticos amenazados de extinción.

Otra técnica de criopreservación, que parece ser más prometedora que la conservación de los embriones en nitrógeno líquido, es la vitrificación. La vitrificación es la solidificación de un líquido logrado por una elevación extrema en viscosidad durante el enfriamiento. Se han obtenido excelentes resultados en la conservación de embriones; sin embargo, sus porcentajes de sobrevivencia no son satisfactorios. Aunque el enfoque del uso de esta técnica es hacia su aplicación en los animales domésticos de importancia económica, en el futuro podrá ser utilizada para la conservación de los recursos genéticos animales en peligro de extinción (32).

La recuperación de ovocitos y la fertilización in vitro de éstos es otra realidad en bovinos y ovinos, sin embargo, es un proceso que requiere cirugía y técnicas de cultivo de órganos (30). Una alternativa es la obtención de ovocitos maduros a partir de la recuperación de ovocitos inmaduros de animales sacrificados. Se ha demostrado que es posible madurar y fertilizar in vitro los ovocitos para luego ser congelados y almacenados en nitrógeno líquido o trasplantados a hembras donadoras de las cuales se producen crías viables $(30,33)$. Esta técnica complementa otros métodos de conservación; por ejemplo, cuando se quiera conservar el genoma de animales que no pueden ser utilizados para la producción de embriones.

El almacenamiento de embriones permitiría que una línea o raza se reconstituyera en una sola generación, mientras que el almacenamiento de semen necesitaría de varias generaciones de retrocruzas (16).

\section{iii. Almacenamiento y transferencia de núcleos y DNA en un banco genético. iii.1) Células de linaje embrionario y transferencia nuclear.}

El núcleo de cada célula contiene toda la información genética. Esto abre la posibilidad de preservar la información genética de un animal en la forma de células o núcleo celular. Recientemente se ha producido la primera oveja clonada (Dolly) a partir de la transferencia de material nuclear de células somáticas a cigoto enucleado no diferenciado. En contraste se ha probado que las células de linaje embrionario, es decir, células procedentes de mórulas y blástulas tempranas conservan su capacidad totipotencial, por lo que se pueden usar para producir embriones completos (34).

En las aves, a diferencia de los mamíferos

Vol. 12/No. 3/Julio-Septiembre, 2001 
JC Segura-Correa, RC Montes-Pérez.

no se han obtenido resultados tan alentadores sobre el congelamiento de óvulos, para propósitos de preservación, debido al gran tamaño y a la estructura de la yema. Sin embargo, Tajima y col. (35) y Naito y col. (36) informan de la obtención de aves quimeras por medio de la transferencia de células germinales primordiales a embriones de pollo, tales células han sido conservadas en congelación o se toman directamente de células blastodérmicas frescas, con estos logros es posible aumentar la variación, y como tal, podría ser una forma de preservar el germoplasma.

La conservación ex situ con animales vivos fuera de su ambiente natural significa que la relativa superioridad en ese ambiente puede reducirse o perderse. Este riesgo debe ser evaluado dentro del contexto de otros riesgos asociados con la conservación in situ. En algunas situaciones la tasa reproductiva y supervivencia de los animales puede ser incrementada en las condiciones de un programa ex situ. Sin embargo, los programas de conservación ex situ e in situ son ambos de valor en la conservación de los recursos genéticos animales, por lo que el uso apropiado de ambos pudiera ser complementario en la conservación de poblaciones pequeñas consideradas de valor.

\section{iii.2) Banco de genes y datos.}

Con la información actual, obtenido de proyectos que tienen por objetivo el mapeo genético del cerdo por ejemplo, se dispone de sondas moleculares conseguidas por medio de clonación de ácidos nucleicos, que permiten identificar marcadores genéticos, los cuales están asociados a loci de características cuantitativas (QTL por sus siglas en inglés). Estos a la vez están involucrados con la expresión de rasgos fenotípicos cuantitativos como el crecimiento y características de la canal. Esta metodología abre nuevas posibilidades para efectuar la selección por medio de marcadores genéticos y también la producción de animales transgénicos (22). Tal información está siendo almacenada en bancos de genes.

Para ello, los bancos de genes y el almacenamiento de espermatozoides y embriones congelados por periodos prolongados de tiempo, abren la posibilidad de mejorar los procesos de conservación ex situ de recursos genéticos animales, principalmente aquellos ubicados en la categoría de riesgo de extinción (32).

La base para un programa de conservación y manejo es el conocimiento de la información sobre razas y tipo de razas, rasgos principales y población, así como el ambiente bajo el cual los animales son utilizados. Una manera de hacer disponible esa información es a través de los bancos de datos. Los bancos de datos pueden ser utilizados para planear la utilización de los recursos genéticos, para monitorear los cambios de "status" genético de las diferentes especies, para el entrenamiento sobre el manejo de los recursos genéticos y para ayudar a definir programas apropiados de cruzamientos y estrategias de utilización de los recursos. La información recopilada en los bancos de datos debe ser corta y simple de tal manera que sean entendidos por otras instituciones o países. Para los que están interesados en el manejo y conservación de las aves criollas se debería integrar un banco de datos uniforme para las distintas instituciones del país y constituir una red de manejo y conservación de las aves criollas. La incorporación de todas las investigaciones con bases de datos nacionales de conservación en recursos genéticos animales podrían ser utilizados en el establecimiento de prioridades y la adopción de decisiones relacionadas con las condiciones agroecológicas de cada región geográfica (11).

Eventualmente, un programa de conservación y manejo de los recursos genéticos animales resultaría en el flujo de tales recursos entre países. Sin embargo, las regulaciones sobre salud animal entre países deben ser tomadas en cuenta.

Los componentes biotecnológicos que apoyan a los programas de conservación ex situ, incluye: marcadores genéticos, DNA nuclear o mitocondrial, mapeo del genoma, manipulación y almacenamiento de semen, oocitos y embriones. Entre los marcadores genéticos ya disponibles se

\section{Revista Biomédica}


Recursos genéticos animales.

cuentan proteínas sanguíneas, proteínas de la leche, antígenos, complejos de histocompatibilidad, enfermedades genéticas monofactoriales, sondas moleculares de secuencia específica $(37,38)$.

El análisis del DNA nuclear y mitocondrial permite importantes aplicaciones tales como el análisis de poblaciones usando polimorfismos genéticos y frecuencias genéticas; la cuantificación indirecta de la consanguinidad en una población donde las relaciones de parentesco se desconocen y la relación entre marcadores genéticos y producción, resistencia a enfermedades y adaptación $(39,40)$.

\section{4.- Costos de la Conservación.}

Los principales costos de la conservación genética incluyen: la identificación y caracterización de ejemplos representativos de las poblaciones de animales que van a ser conservados; el mantenimiento de grupos de genes en poblaciones vivas y/o la colección y preservación de gametos y embriones; administración de los programas de conservación; y la menor producción de las poblaciones conservadas (41).

La menor producción de las poblaciones conservadas y su falta de competencia en los sistemas comerciales es a menudo la razón por la cual se encuentran en riesgo de ser desplazados por animales con valor comercial. Presumiblemente, esos animales superiores comercialmente se continuaran mejorando, por lo tanto, la probabilidad de que los animales conservados tengan un valor comercial en el futuro descansa en los posibles cambios en el ambiente o requerimientos del mercado. Smith (42) considera que sólo si se espera una ganancia de 5 a $10 \%$ en eficiencia económica, valdría la pena conservar a las especies nativas con fines económicos.

Estos argumentos económicos en contra de la conservación de las especies conservadas tiene sentido con relación a las razas bien caracterizadas de los paises desarrollados. Sin embargo, no son tan válidos para los paises en desarrollo en los cuales los sistemas y comportamientos productivos de las razas adaptadas no han sido caracterizados debidamente y continuan siendo utilizados.

\section{CONCLUSIÓN.}

A pesar de los avances tecnológicos como la identificación y transferencia de genes, la maduración y fertilización in vitro de gametos, la conservación y transferencia de embriones o la clonación, lo esencial es la disponibilidad de material genético, del cual los animales nativos o criollos son una fuente importante. Es una práctica común en los sistemas de mejoramiento genético actual que cuando existen limitaciones al mejoramiento a través de la selección y cruzamiento de las líneas mejoradas, siempre se buscan nuevos genes en el material nativo, por ejemplo, para resistencia a enfermedades, que normalmente se encuentran en esas poblaciones. He aquí la necesidad de mantener los recursos genéticos animales como amortiguadores frente a los cambios climáticos, presencia de nuevas enfermedades o modificaciones en el mercado; tales recursos genéticos representan un factor que disminuye los riesgos de la pérdida de alimentos y satisfactores para las generaciones actuales y futuras.

\section{REFERENCIAS.}

1.- Otero OLD. Biodiversidad: Consideraciones introductorias. En: Alonzo ME, editor. La Biodiversidad Neotropical. Mérida, Venezuela: Grupo de Química Ecológica; 1992. p. 1-14.

2.- Segnini S. Medición de la Diversidad de especies. En: Alonzo ME, editor. La Biodiversidad Neotropical. Mérida, Venezuela: Grupo de Química Ecológica; 1992. p. 95-118.

3.- Alonso ME. Biodiversidad y Quimiodiversidad. En: Alonzo ME, editor. La Biodiversidad Neotropical. Mérida, Venezuela: Grupo de Química Ecológica; 1992. p. 119-60.

4.- UICN, PNUMA y WWF. Cuidar la Tierra. Estrategia para el futuro de la vida. Suiza: Gland; 1991. p. 142.

5.- Organización de las Naciones Unidas para la 


\section{JC Segura-Correa, RC Montes-Pérez.}

Agricultura y la Alimentación (FAO). Conservación de los recursos genéticos en la ordenación de los bosques tropicales. Serie Montes. Monografía No. 107. Roma: FAO; 1995. p. 37.

6.- Hodges J. Animal genetic resources. Impact Sci Soc 1990; 158:143-53.

7.- Hammond K. Conservation of Domestic Animal Diversity: Global Overview. In: Smith C, Gavora JS, Benkel B, Chesnais J, Fairfull W, Gibson JP, Kennedy BW, Burnside EB, editors. Proceedings of the World Congress on Genetics Applied to Livestock Production. Vol. 21. Guelph, Ontario, Canada: University of Guelph; 1994. p. 610.

8. Cundiff LV. Evaluación y utilización de razas de ganado bovino europeas y cebuinas para producción de carne. En: Consejo Nacional de los Recursos Genéticos Pecuarios A.C., editores. Ciclo de Conferencias sobre Evaluación, Comercialización y Mejoramiento Genético. Tuxtla Gutiérrez, Chiapas, México: Consejo Nacional de los Recursos Genéticos Pecuarios A.C.; 2000. p. 44-60.

9.-Organización de las Naciones Unidas para la Agricultura y la Alimentación (FAO). Expert consultation on the management of global animal genetic resources. Report. Roma: FAO; 1992. p. 43

10. CATIE. Regional Program on Animal Genetic Resources Conservation and Management in Latin America and the Caribbean. Centro Agronómico Tropical de Investigación y Enseñanza. Turrialba, Costa Rica: CATIE; 1992. p. 45-67.

11.- Alonso MRA., Ulloa AR. Hacia un proyecto nacional de investigación en genomas de animales domésticos. Vet Mex 1997; 28: 365-70.

12.-Azuara PB, Velázquez EA, Ayala BF, Garza RJ. Polimorfismo bioquímico de las proteínas sanguineas en bovinos criollos y su aplicación en la selección. En: Facultad de Medicina Veterinaria y Zootecnia, Universidad Nacional Autónoma de México, Citogenética e Inmunogenética. México D.F.; 1982. p. 60-7.

13.-Segura-Correa JC. Estado actual y comportamiento de las aves cuello desnudo en México. En: Consejo Nacional de los Recursos Genéticos Pecuarios A.C., editores. IV Congreso Iberoamericano de razas autóctonas y criollas. Tampico, Tamaulipas; México : Consejo Nacional de los Recursos Genéticos Pecuarios A.C., 1998. p. 247-55.
14.-Pomareda CP, Pérez EG. Perspectivas en los mercados y oportunidades para la inversión en ganadería. En: Consejo Nacional de los Recursos Genéticos Pecuarios A.C., editores. Ciclo de Conferencias sobre Evaluación, Comercialización y Mejoramiento Genético. Tuxtla Gutiérrez, Chiapas, México: Consejo Nacional de los Recursos Genéticos Pecuarios A.C.; 2000. p. 2-17. 31.

15.- Comte M-Ch. Opciones vitales. Ceres. 1991; p. 1720.

16.- Lake P.E. The history and future of the cryopreservation of avian germ plasm. Poultry Sci 1986; 65:1-15.

17.- Steane DE. Note on the FAO Expert Consultation on Management of Global Animal Genetic Resources. Rome: FAO; 1992. p. 39.

18.-Frisch JE, Vercoe JE. Consideration of adaptive and productive components of productivity in breeding beef cattle for tropical Australia. II World Congress on Genetics Applied to Livestock Production. Madrid, Spain; 1982; 3:307-21.

19.- McKusick VA. Current trends in mapping human genes. Faseb J 1991; 5:12-20.

20.- Bishop MD, Kappes SM, Keele JW, Stone RT, Sunden SLF, Hawkins GA, et al. A genetic linkage map for cattle. Genetics 1994; 136:619-39.

21.- Rohrer GA, Alexander LJ, Keele JW, Smith TB, Beattie CW. A microsattelite linkage of the porcine genome. Genetics 1994; 136:231-45.

22.- Casas CE, Kirkpatrick WB. Regiones genómicas asociadas con crecimiento en cerdos. Vet Mex 1998; 29:181-9.

23.- Lozano-Romo L. Análisis de la explotación avícola a nivel tradicional en el poblado C-28 del Plan Chontalpa, Tabasco. Tesis de licenciatura. Colegio Superior de Agricultura Tropical. H. Cárdenas, Tabasco; 1982. p. 97.

24.- Grande-Cano JD. Estudio descriptivo de la producción avícola en el ejido Vicente Guerrero, Teapa, Tabasco. Tesis de licenciatura. Colegio Superior de Agricultura Tropical; H. Cárdenas, Tabasco; 1982. p. 134.

25.- Berdugo-Rejón JG. Estudio de la ganadería familiar en el municipio de Sucila, Yucatán. Tesis de Maestría en Ciencias. Colegio de Postgraduados; Montecillos, Estado de México; 1987. p. 145.

\section{Revista Biomédica}




\section{Recursos genéticos animales.}

26.- Sandoval VFC. Estudio del polimorfismo genético de algunas proteínas sanguineas en bovinos criollos mexicanos. Tesis de Licenciatura. Universidad Nacional Autonoma de Mexico, D.F. 1981; p. 86.

27.- Rebollo AAG, Acosta RR, Velázquez EA, Atilano LD, Pérez RH. Polimorfismo genético de los sistemas de albúminas, hemoglobinas y transferrinas en ganado híbrido Holstein-Cebú en el trópico mexicano. Vet Mex 1994; 25 : 255-9.

28.-Folch P, Jordana J. 1998. Demographic characterization, inbreeding and maintenance of genetic diversity in the endangered Catalonian donkey breed. Genet Sel Evol 1998; 30: 195-201.

29.- Smith C. Genetic aspects of conservation in farm livestock. Livestock Prod Sci 1984; 11:37-48

30.- Brem G. Future Biotechnological possibilities in preserving animal germplasm. Hannover: FAO Workshop; 1990. p. $149-59$.

31.- Polge C. Cryogenic Storage of Mammalian Cells. In: Editores. Animal Genetic Resources Conservation and Management. Proceedings of the FAO/UNEP Technical Consultation. Animal Production and Health Paper No. 44/ 2. Rome: FAO; 1984. p. 43-7.

32.-Rall FR. Guidelines for establishing animal genetic resource banks: Biological materials. Management and facility considerations. In: D.L. Armstrong and T.S. Gross, editors. Proceedings Wild Cattle Symposium. Omaha: Omaha's Henry Doorly Zoo; 1991. p. 46-106.

33.- Holm P, Walker SK, Seamark RF. Embryo viability, duration of gestation and birth weight in sheep after transfer of in vitro matured and in vitro fertilized zygotes cultured in vitro or in vivo. J Reprod Fertil. 1996; 107:175-81.

34.- Du F, Giles JR, Foote RH, Graves KH, Yang X, Moredith RW. Nuclear transfer of putative rabbit embryonic stem cells leads to normal blastocyst development. J Reprod Fertil 1995; 104:219-23.

35.- Tajima A, Naito M, Yasuda Y, Kuwana T. Production of germ line chimera by transfer of primordial germ cells in domestic chicken (Gallus domesticus). Theriogenology 1993; 40: 509-19.

36.- Naito M, Tajima A, Tagami T, Yasuda Y, Kuwana T. Preservation of chick primordial germ cells in liquid nitrogen and subsequent production of viable offsprings. $\mathbf{J}$
Reprod Fertil 1994; 102: 321-25.

37.-Teale AJ, Tan SG, Tan JH. Applications of molecular genetic and reproductive technologies in the conservation of domestic animal diversity. In: Smith C, Gavora JS, Benkel B, Chesnais J, Fairfull W, Gibson PJ, Kennedy BW, Burnside EB, editors. Proceedings of the 5 th World Congress on genetics applied to livestock production. Vol. 21 Gene mapping, polimorphism, transgenes, nonconventional genetics, conservation of domestic animal genetic resource. Ontario, Canada: University of Guelph; 1994. p. 493-500.

38.-Kappes SM. 1999. Utilization of gene mapping information in livestock animals. Theriogenology 1999; 51:135-47.

39.-Jordana J, Piedrafita J. 1996. The "Bruna dels Pirineus (Pyrenian brown breed): a genetic study of a rare cattle breed in Catalonian (Spain). Biochem Syst Ecol 1996; 24: 485-98.

40.-Alonso MR. La industria animal en el nuevo milenio: Aplicaciones de la clonación de individuos, animales transgénicos y marcadores genéticos en la ganadería. En: Consejo Nacional de los Recursos Genéticos Pecuarios A.C., editores. Ciclo de Conferencias sobre Evaluación, Comercialización y Mejoramiento Genético. Tuxtla Gutiérrez, Chiapas, México: Consejo Nacional de los Recursos Genéticos Pecuarios A.C.; 2000. p. 98-106.

41.- Fitzhugh HA. Genetic Aspects of Germplam Storage and Genetic Engineering. In: editores. Animal Genetic Resources: Cryogenic Storage of Germplasm and Molecular Engineering. Animal Production and Health Paper No. 44/ 2. Rome: FAO;1984. p. 211

42.- Smith C. Estimated costs of genetic conservation in farm animals. In: editores. Animal Genetic Resources Conservation and Management. Proceedings of the FAO/ UNEP Technical Consultation. Animal Production and Health Paper No. 44/1. Rome: FAO;1984. p. 44.

43.-Falconer DS. Introducción a la Genética Cuantitativa. México: Editorial Continental S.A.; 1970. p. 265.

Vol. 12/No. 3/Julio-Septiembre, 2001 